This item was submitted to Loughborough's Research Repository by the author.

Items in Figshare are protected by copyright, with all rights reserved, unless otherwise indicated.

\title{
Predicting stereolithography injection mould tool behaviour using models to predict ejection force and tool strength.
}

PLEASE CITE THE PUBLISHED VERSION

\section{PUBLISHER}

(C) Taylor and Francis

\section{LICENCE}

CC BY-NC-ND 4.0

\section{REPOSITORY RECORD}

Hopkinson, Neil, and Phill M. Dickens. 2019. "Predicting Stereolithography Injection Mould Tool Behaviour Using Models to Predict Ejection Force and Tool Strength.". figshare. https://hdl.handle.net/2134/3544. 
This item was submitted to Loughborough's Institutional Repository by the author and is made available under the following Creative Commons Licence conditions.

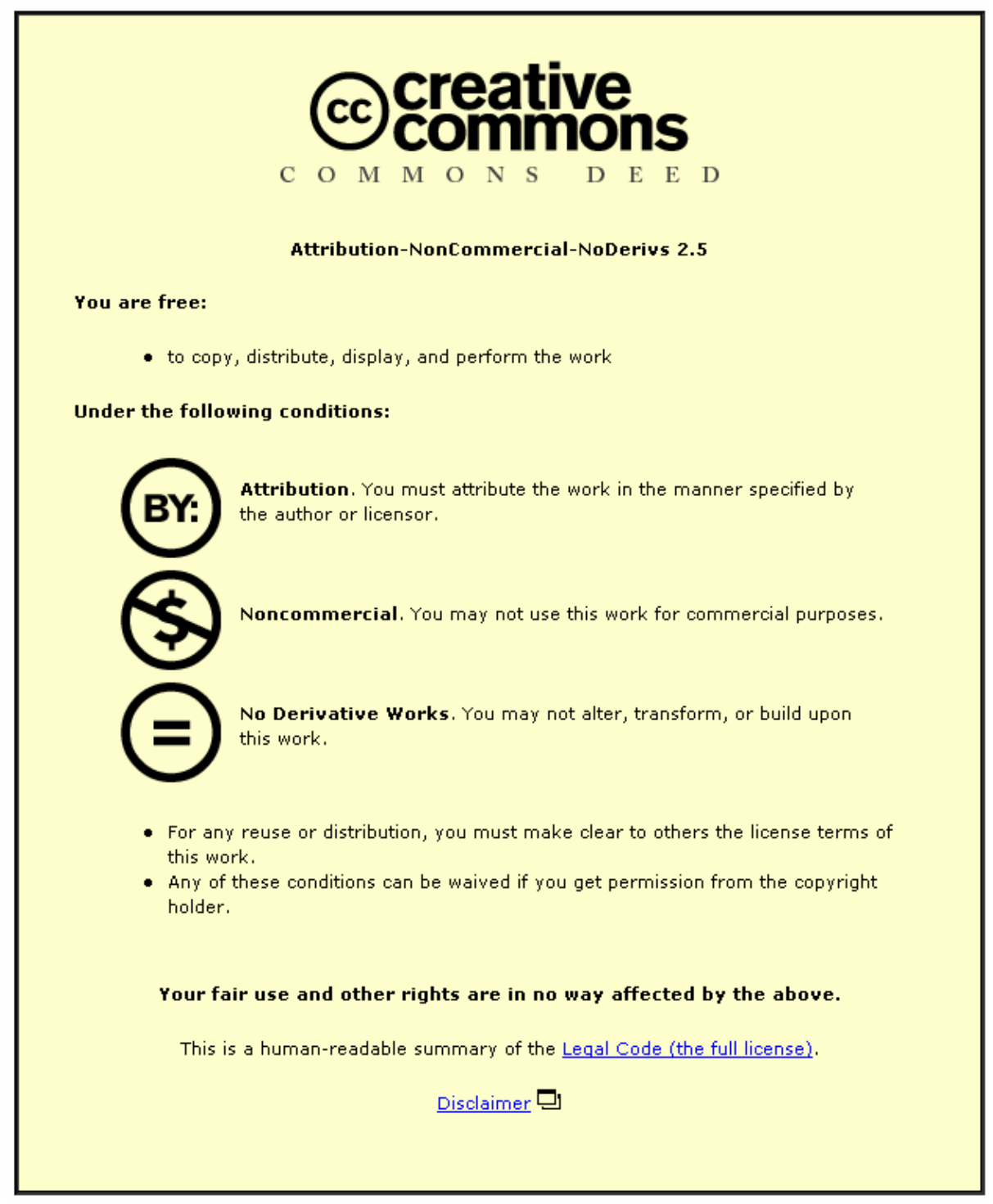

For the full text of this licence, please go to: http://creativecommons.org/licenses/by-nc-nd/2.5/ 


\title{
Predicting Stereolithography Injection Mould Tool Behaviour Using Models to Predict Ejection Force and Tool Strength.
}

Neil Hopkinson (corresponding author) is a Lecturer in the Rapid Manufacturing Research Group, Department of Mechanical and Manufacturing Engineering, Queens Building, De Montfort University, Leicester, LE1 9BH, UK.

Tel : +44 $1162551551 \times 8064$

Phill Dickens is the Professor of Manufacturing Technology in the Department of Mechanical and Manufacturing Engineering at De Montfort University, Leicester, UK.

\begin{abstract}
The work reported involved Finite Element Analysis (FEA) modelling of heat transfer in a stereolithography (SL) tool and then performing a series of experiments to measure true heat transfer in the tool. The results from the practical measurement of heat transfer were used to validate and modify the FEA model. The results from the modified FEA model were then used to predict the tensile strength of the tool at various stages after injection of the thermoplastic melt.

Previously developed equations to predict ejection forces were used to estimate the ejection forces required to push the moulding from the SL core. During the practical experiments the true ejection forces were measured.
\end{abstract}


The combination of predicted tool strength and ejection forces were intended to be used a basis for to determine whether certain SL tool designs will fail under tension during part ejection. This would help designers and manufacturers to decide whether SL tooling is suitable for a specific application.

The initial FEA heat transfer model required some modifications and the measured ejection forces were higher than the predicted values, possible reasons for these discrepancies are given. For any given processing conditions there was an inherent variance in the ejection forces required however longer cooling periods prior to ejection resulted in higher ejection forces.

The paper concludes that, due to the variations in required ejection forces, a reliable tool to predict tensile failure will be difficult to produce however improved performance may be gained by adopting processing conditions contrary to those recommended in the current process guidelines. 


\section{Introduction}

Rapid Prototyping (RP) processes are ones which are used to create three dimensional (3D) objects directly from CAD data using the principle of stacking 2 dimensional layers of materials on top of each other. In the last 10 years a family of RP processes have been developed and have resulted in considerable reductions in the times needed to develop new products. RP parts may be used during various stages of the product development cycle including:

- basic prototypes for visualisation using processes such as Fused Deposition Modelling (FDM), 3D Printing and Wax Jetting.

- $\quad$ master patterns to create prototype tooling in processes such as vacuum casting and investment casting.

- $\quad$ tools for short run injection moulding using processes such as SL and selective laser sintering (SLS).

Stereolithography is considered to be the original and one of the leading RP technologies. The SL process starts in the same way as all the other RP processes with a 3D CAD model of a part required in .stl (surface tessellation) format. The CAD model is sliced into a number of layers which may typically be between $0.025 \mathrm{~mm}$ and $0.15 \mathrm{~mm}$ thick. The solid part is created when a laser, which is driven by the CAD data, selectively passes over the surface of a vat of uncured photosensitive epoxy resin. The laser initiates a reaction in the resin causing it to solidify and so a solid 2D epoxy profile is created. The solid 2D profile is attached to a platform which is lowered by the required layer thickness in the vat. A subsequent 
layer is attached to the top of the previous layer when the laser selectively passes over the surface of the resin once more. The process is repeated until a solid epoxy part has been made. In most cases the solid epoxy part is subjected to some finishing and further curing in an ultraviolet oven. SL is particularly adept at producing shapes with complicated geometries and features such as deep slots which are difficult to machine.

The SL process may be used to create injection moulding tooling into which plastic material will be injected. The main reason for using SL tools is to injection mould prototype parts in the final production material using the final production process in a fraction of the time and at a reduced cost when compared with using conventionally machined metal tooling (Jacobs 1996). SL tools are less robust than metal ones and the main problem encountered when using them is that they break during moulding, and this can be due to many reasons. SL tools have material properties such as tensile strength and Young's Modulus which are considerably lower than those for metals such as aluminium or steel. The problem is exacerbated by increases in tool temperature, which result in further reductions in mechanical properties (Hague 1997), when hot plastic is injected. The low thermal conductivity of SL tools has also been cited as a problem resulting in increased cycle times and the tendency of operators to inject material while the tool is still hot and therefore weak (Jacobs 1996). 


\section{Background}

The phenomenon of tensile tool failure as shown in Figure 1 was identified as a critical weakness when using SL injection moulding tools. Tensile tool failure occurs when the ejection force exceeds the tensile strength of the core and so by predicting both the tool strength and the ejection force it should be possible to predict if a tool will fail in tension during part ejection.

[Insert Figure 1]

\subsection{Tool Strength}

The strength of a core feature in an SL tool is governed by both its ultimate tensile strength (UTS) and its cross sectional area as shown below:

Core feature strength $=U T S_{t} * A$

Where $U T S_{t}=$ the UTS of the tool material

$A \quad=$ the cross sectional area of the core feature

The equation shown above highlights the importance of the cross sectional area of the core with regard to its resistance to a tensile force applied (such as that encountered during part ejection). However the UTS of cured SL resin is known to vary with temperature (Hague 1997) and it was important to account for this when predicting tool strength. Figure 2 shows how the UTS of SL5170 SL resin decreases at elevated 
temperatures and this decrease in UTS was accounted for in the model to predict tool strength.

[Insert Figure 2]

\section{$2.2 \quad$ Ejection Forces}

Equations to predict the ejection force in traditional injection moulding tools have been proposed (Menges and Morhen 1986, Glanville and Denton 1965, Burke and Malloy 1991) however none of these refer specifically to the use of epoxy tools.

The equation proposed by Glanville and Denton was simplified algebraically (Hopkinson 1999) and is shown below.

$$
F_{e}=\frac{\alpha \cdot\left(T_{m}-T_{e}\right) \cdot L \cdot E \cdot \mu \cdot \pi}{(1 / 2 t-\gamma / 4 t)}
$$

Where:

$F_{e}=$ Ejection Force $(\mathrm{N})$

$\alpha=$ coefficient of thermal expansion of moulding material $\left(\mathrm{K}^{-1}\right)$

$T_{m}=$ melting temperature of moulding material $\left({ }^{\circ} \mathrm{C}\right)$

$T_{e}=$ ejection temperature of moulding material $\left({ }^{\circ} \mathrm{C}\right)$

$L=$ length of core (mm)

$E=$ Youngs Modulus of moulding material at $T e(\mathrm{MPa})$

$\mu=$ coefficient of friction between moulding material and core

$t=$ thickness of moulding (mm)

$\gamma=$ Poisson's ratio for moulding material 
The equations to predict ejection force all suggest that the use of longer cooling times will lead to higher ejection forces, this is significant in the case of SL tools where existing guidelines suggest the use of an extended cooling time prior to part ejection (Decelles and Barrit 1996).

\subsection{Generic Tool Design}

The practical experiments involved moulding a series of parts shown in Figure 3. The moulding was designed to represent a circular boss as this is the type of feature which is likely to fail in tension during part ejection. The diameter at the base of the core was $16 \mathrm{~mm}$, the length of the core was $38 \mathrm{~mm}$ and the wall thickness was uniform at $2 \mathrm{~mm}$. Using a circular boss allowed for simpler modelling and ensured that shrinkage onto the core would be uniform.

[Insert Figure 3]

\section{$3 \quad$ Methodology}

\subsection{Experimental Measurement of Heat Transfer Through the Tool}

Four K type thermocouples were inserted into the SL core in the positions shown in Figure 4. Liquid SL resin was injected around the ends of the thermocouples and the core was then sent for post curing to ensure that the thermocouples were in good thermal contact with the body of the tool. Readings were taken at 1 second intervals from the thermocouples and recorded using a data acquisition set up programmed in HPVee visual programming software. 


\section{[Insert Figure 4]}

\subsection{Modelling Heat Transfer}

A transient heat transfer FEA model was created using the Algor software package with a 2 dimensional axis-symmetrical model of the tool and moulding used in the experiments. The model included a tight mesh at the boundaries between the tool and the moulding as this is where the steepest temperature gradients were anticipated. The model was loaded with material data (density, coefficient of thermal conductivity and specific heat capacity (SHC)) for the materials to be used in the experiments.

The tool material used in the experiments was SL5170 epoxy resin built in the $\mathrm{ACES}^{\mathrm{TM}}$ build style and the moulding material was polypropylene with a melting temperature of $160^{\circ} \mathrm{C}$. The polypropylene had been successfully injected into the SL tool at a temperature of $180^{\circ} \mathrm{C}$ in the experiments. For this reason, a starting temperature of $170^{\circ} \mathrm{C}$ (the midpoint between the injection and freezing temperatures) was applied to the nodes representing the polypropylene in the model. An initial tool temperature of $55^{\circ} \mathrm{C}$ was applied to the nodes representing the tool material as this was the tool temperature at which shots were injected in the experiments. The model was run using 0.1 second time increments between successive calculations of heat transfer for a total of 120 seconds. The model was modified to replicate the true heat transfer using the results from the practical measurement of tool temperatures. 


\subsection{Using Results from the Heat Transfer Analysis to Predict Tool Strength}

The predictions for tool strength were based on the temperature output from the modified FEA model of heat transfer in the tool together with the known relationship between SL resin temperature and UTS shown in Figure 2.

Figure 5 shows how the results from the FEA model were used to predict tool strength at different times after injection. The example in Figure 5 assumes that the FEA model included 4 nodes from the central axis to the edge of the core. This would result in the core being split into three separate rings with outside radii of $R_{1}, R_{2}$ and $\mathrm{R}_{3}$. The actual values the radii depend on the positions of the nodes in the FEA model.

\section{[Insert Figure 5]}

The left hand side of the diagram in Figure 5 shows a schematic of part of the FEA heat transfer model. The right hand side of the diagram shows how the positions of the nodes in the FEA model may be used to split the cross sectional area of the core into a series of rings in order to predict tool strength. At any time during the running of an FEA heat transfer model each node stores a value of the temperature at that point in the model. This means that for any time after a model has started running the tensile strength of each of the rings may be calculated individually by the method shown below: 
1. Allocate each ring its own temperature.

Outer ring temperature $=($ Temp at Node $1+$ Temp at Node 2$) / 2$

Middle ring temperature $=($ Temp at Node $2+$ Temp at Node 3$) / 2$

Inner Circle temperature $=($ Temp at Node $3+$ Temp at Node 4$) / 2$

(note that this method interpolates the temperature distribution between two adjacent nodes assuming a linear gradient, in reality this is not true but with a sufficiently tight mesh the method is adequate for estimating tool strength.)

2. Find the UTS (MPa) of each ring

The tensile strength of SL5170 resin may be calculated by the following equation where $T_{r}$ is the temperature of the resin (see Figure 2):

$$
U_{T S} S_{S L 5170}=-0.00005 T_{r}^{3}+0.0176 T_{r}^{2}-2.2025 T_{r}+93.659
$$

3. Find the tensile strength $(\mathrm{N})$ of each ring.

The tensile strength of each ring was calculated as the product of its area and its UTS using the equations below:

Tensile Strength $\mathrm{outer} \mathrm{ring}=\pi\left(\mathrm{R}_{1}{ }^{2}-\mathrm{R}_{2}{ }^{2}\right) . U T S_{\text {outer ring }}$

Tensile Strength $h_{\text {middle ring }}=\pi\left(\mathrm{R}_{2}{ }^{2}-\mathrm{R}_{3}{ }^{2}\right) . U T S_{\text {middle ring }}$ 
Tensile Strength $\mathrm{inner} \mathrm{circle}=\pi \mathrm{R}_{3}{ }^{2}$.UTS inner circle

The overall tensile strength of the whole core could then be calculated by adding together the separate strengths calculated above.

\subsection{Predicting Ejection Forces}

The values for each of the variables inserted into the equation to predict ejection force are listed in Table 1. Most of the values are based on the known dimensions of the tool or published material data. The value for the ejection temperature of the moulding (Te), however was based on the values given by the FEA model at different times after it had started running.

[Insert Table 1]

\subsection{Experimental Measurement of Ejection Forces}

The mould set used in the experiments included 3 equally spaced ejector pins to push the base of the moulding from the core after it had cooled sufficiently. A load cell was housed behind each of the ejector pins so that the ejection force could be measured for each moulding (see Figure 6). The readings from the load cells were recorded at a frequency of $1000 \mathrm{~Hz}$ using a data acquisition system programmed in the HPVee visual programming language. A number of different cooling times prior to ejecting the part were used to assess their effect on the ejection force. The ejection force results were used to verify the equation developed to predict ejection forces. 
[Insert Figure 6]

\section{$4 \quad$ Results}

\subsection{Modelled and Measured Heat Transfer}

The heat transfer model was run and the temperature outputs from nodes in identical positions to the thermocouples in the real tool were recorded. The FEA model was updated due to discrepancies between the model's output and the measured tool temperatures. In particular there appeared to be more heat transferred to the core in the real tool than in the FEA model. The reason for the higher heat transfer recorded from the tool was attributed to the shrinkage of the moulding onto the core. As the moulding contracted onto the core it lost thermal contact with the cavity half of the mould and so the majority of the heat in the moulding was transferred into the core half of the mould.

The FEA model was re-run using different values for the SHC of the SL resin in order that the temperature cycles from the FEA model more closely matched those from the practical experiments. The results from the updated model matched the experimental measurements more closely making the output from this model more suitable for the prediction of tool strength as described earlier.

\subsection{Predictions of Tool Strength}

The results from the updated FEA model were used to predict the tensile strength of the tool at various times after starting the model. This could then be used as a guide for tool strength at various times after injection of the polypropylene. Figure 7 shows the results of the predictions of tool strength at various times after injection. At the 
time of melt injection when the core is at $55^{\circ} \mathrm{C}$ the its predicted tensile strength is at its maximum at $3000 \mathrm{~N}$. However the predicted tensile strength of the core falls exponentially to a minimum value of $1300 \mathrm{~N} 120$ seconds after melt injection. The model shows that the longer the period between melt injection and part ejection, the weaker the tool, this is significant given the recommendations for longer cooling times (Decelles and Barrit 1996).

[Insert Figure 7]

\subsection{Predicted and Measured Ejection Forces}

Figure 8 shows the predicted ejection forces along with the recorded values for various cooling times prior to part ejection. None of the ejection forces were greater than the anticipated tensile strength of the core and accordingly, the core never failed in tension during ejection.

\section{[Insert Figure 8]}

As expected, longer cooling times lead to higher ejection forces due to increased contraction of the moulding onto the core. The predicted ejection forces are around $30 \%$ lower than the measured values, this may be due to the fact that some of the parameters used in the equation such as the coefficient of friction, Young's Modulus and the part temperature at ejection were estimates based on the best available data. This indicates that the equation and values may only be used as a rough estimator and not as an accurate predictor of ejection force. 
The measured ejection forces show some inherent variation from $50-150 \mathrm{~N}$ for any given cooling time prior to ejection. Given that all parameters were kept consistent for each shot and the core's surface was not subject to any smoothing during use there is no clear explanation for this inherent variation in results.

\section{Discussion}

The modelling work resulted in predictions of tool strength and ejection forces which could theoretically be used to decide if an SL tool should be employed or not. The practical work showed that a number of parts could be successfully injection moulded with no apparent damage to either the tool or the mouldings. The results from the practical work indicated some discrepancies with the predicted results which are discussed below. Further findings which had not been anticipated are also discussed along with recommendations for further work.

\subsection{Differences between modelled and measured heat transfer}

The differences between the measured tool temperatures and those given by the initial FEA model indicated that the FEA method did not result in a simple, accurate prediction of heat transfer for this system. The modified model was used to provide data to predict tool strength however with different geometries the change to the SHC values may not be applicable and the FEA output would probably be inappropriate for predictions of tool strength. In addition, different moulding materials, with different shrinkage characteristics, would result in variations in the amount of heat transferred into the two halves of a mould. For this reason, standard FEA packages for heat 
transfer do not provide a useful method for predicting heat transfer and therefor tool strength in SL tools.

\subsection{Differences between Measured and Predicted Ejection Forces}

The predicted ejection forces were lower than the measured values however the rate of increase due to increased cooling times appeared to be reasonably consistent for both. This suggests that slight changes, such as a scale factor, to the equations to predict ejection force may result in more accurate predictions. The inherent variation of measured ejection forces for any given cooling time prior to ejection does mean that accurate predictions of the ejection force will be difficult to make even with a modified equation. Geometric changes, such as from a circular cross section to a square one, will change the nature of the moulding's shrinkage onto the core and therefore affect the ejection force and the equation needed to predict it.

\subsection{Creating a model to predict tensile tool failure}

The difficulties highlighted above with regard to prediction of ejection force and tool strength mean that an accurate model to predict tensile tool behaviour during part ejection will be difficult, if not impossible, to create. An accurate method for predicting heat transfer would significantly improve the possibility of predicting tool strength closely. However the modelling work along with the practical results has helped to identify ways in which the likelihood of tensile tool failure during ejection may be minimised and details are given below. 


\subsection{The effects of cooling time prior to ejection}

The ejection force results clearly show how a longer cooling time prior to ejection results in a higher ejection force - this suggests that an early ejection would minimise the risk of tensile tool failure. In addition, the predictions for tool strength based on the data from the more accurate modified FEA model show how the tool gets weaker with longer cooling times prior to ejection. These two points suggest that ejection should be performed as early as possible to minimise the risk of tensile tool failure - a suggestion which directly contradicts the published procedural guidelines (Decelles and Barrit 1996). It is important, however, that too short a cooling time is not employed as this will result in damage to the moulding either by pushing it in it's molten state or while it will be subject to out of mould warpage.

\subsection{Suggestions for further work}

The low thermal conductivity which had previously been regarded as a weakness in SL tools was shown to delay thermal weakening of the tool and therefore aid the process if a short cooling time prior to ejection is adopted. By thinking of the low thermal conductivity of SL moulds as an advantage further benefits of the use of SL tools may be considered. Firstly, the low thermal conductivity reduces the possibility of the melt freezing off which may allow deep thin ribs to be moulded more easily than with metal tools. This potential benefit is particularly appropriate as the SL process is capable of producing deep slots far more easily than machining. Secondly the low thermal conductivity means that the melt can be injected into a tool under low pressures without the risk of shutting off. This brings about the possibility of using SL tools on relatively low rated injection moulding machines to produce much larger mouldings than would be possible with metal tools. This would allow prototype tools 
to be tested on small research injection moulding machines without the need to stop production on larger production machines. 


\section{References}

Burke, C. and Malloy, R., 1991, Proceedings from the $49^{\text {th }}$ ANTEC Conference, Montreal, Canada, May 1991, Published by the Society of Plastics Engineers, pp 1781-1787

Decelles, P. and Barrit, M., 1996, Direct AIM ${ }^{\mathrm{TM}}$ Prototype Tooling Procedural

Guide, 3D Systems, Valencia, California, USA, P/N 70275/11-12-96

Frank, H.P., 1969, Polypropylene., MacDonald Technical \& Scientific, London, 1969, SBN 356026310

Glanvill, A and Denton, E., 1965, Injection Mould Design Fundamentals. Industrial Press, New York.

Hague, R.J.M., 1997, The Use of Stereolithography Models as Thermally Expendable Patterns in the Investment Casting Process, Ph.D. Thesis submitted to the University of Nottingham, UK.

Hopkinson, N., 1999, Investigation into Part Ejection and Heat Transfer in the Direct AIM $^{\mathrm{TM}}$ Process, Ph.D. Thesis submitted to De Montfort University, UK.

Jacobs, P.F., 1996, Recent Advances in Rapid Tooling from Stereolithography. Proceedings of the National Conference on Rapid Prototyping and Tooling Research, Buckinghamshire College, UK, November 18-19, ISBN: 0852989822 
Kalpakjian, S., 1991, Manufacturing Processes for Engineering Materials, Addison-Wesley Publishing Company, USA, ISBN 0-201-50806-0

Menges, G., Morhen, P., 1986, How to Make Injection Moulds, Hanser Publishers, New York, 1986, ISBN 3-446-13666-5

Henrik Reitz, H. 1999, Comparative wear testing of SL material against SL material and aluminium relatively, Report from the Danish Technolocical Institute Tribology Centre, May $31^{\text {st }} 1999$.

Solvay, 1994, Material Data for ELTEX ${ }^{\mathrm{TM}}$ P RW 261 Polypropylene, Printed 06/94. Rue de Prince Albert 33, B-1050, Brussels, Belgium 


\begin{tabular}{|c|c|c|c|}
\hline Variable & Value & Units & Source \\
\hline$\alpha$ & $6.8 \times 10-5$ & $\mathrm{~K}^{-1}$ & Frank (1969) \\
\hline$T_{m}$ & 160 & ${ }^{\circ} \mathrm{C}$ & Solvay (1994) \\
\hline$T_{e}$ after 20 seconds cooling & 142 & ${ }^{\circ} \mathrm{C}$ & FEA Output \\
\hline$T_{e}$ after 40 seconds cooling & 137 & ${ }^{\circ} \mathrm{C}$ & FEA Output \\
\hline$T_{e}$ after 60 seconds cooling & 135 & ${ }^{\circ} \mathrm{C}$ & FEA Output \\
\hline$T_{e}$ after 80 seconds cooling & 133 & ${ }^{\circ} \mathrm{C}$ & FEA Output \\
\hline$T_{e}$ after 100 seconds cooling & 132 & ${ }^{\circ} \mathrm{C}$ & FEA Output \\
\hline$T_{e}$ after 120 seconds cooling & 131 & ${ }^{\circ} \mathrm{C}$ & FEA Output \\
\hline$L$ & 38 & $\mathrm{~mm}$ & \\
\hline$E$ at $T_{e}$ & 245 & $\mathrm{MPa}$ & Frank (1969) \\
\hline$\mu$ & 0.88 & & Reitz (1999) \\
\hline$t$ & 2 & $\mathrm{~mm}$ & \\
\hline$\gamma$ & 0.35 & & Kalpakjian (1991) \\
\hline
\end{tabular}

Table 1. Values Inserted into the equation to predict ejection force 
ejector pins push forward

core breaks

moulding sticks to core

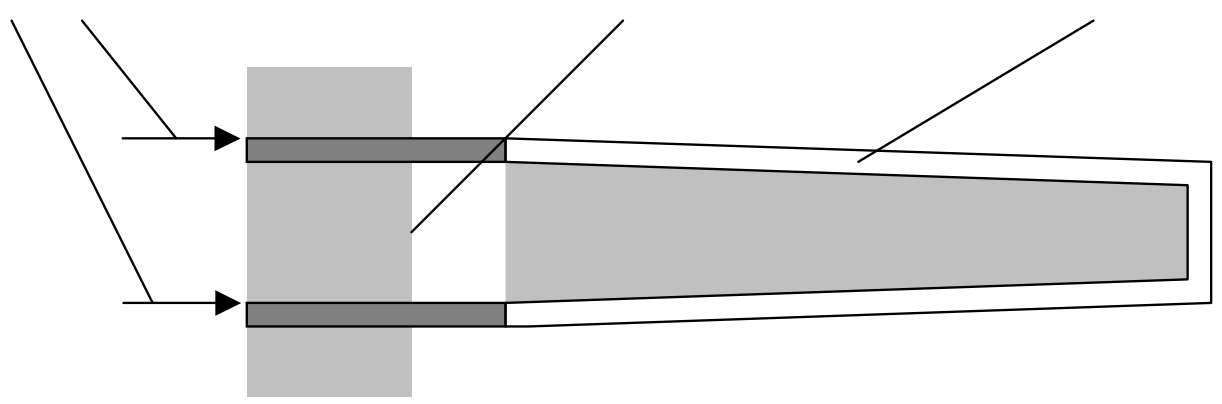

Figure 1. Diagram Showing How Contraction of a Moulding onto a core results in Tensile Tool Failure 


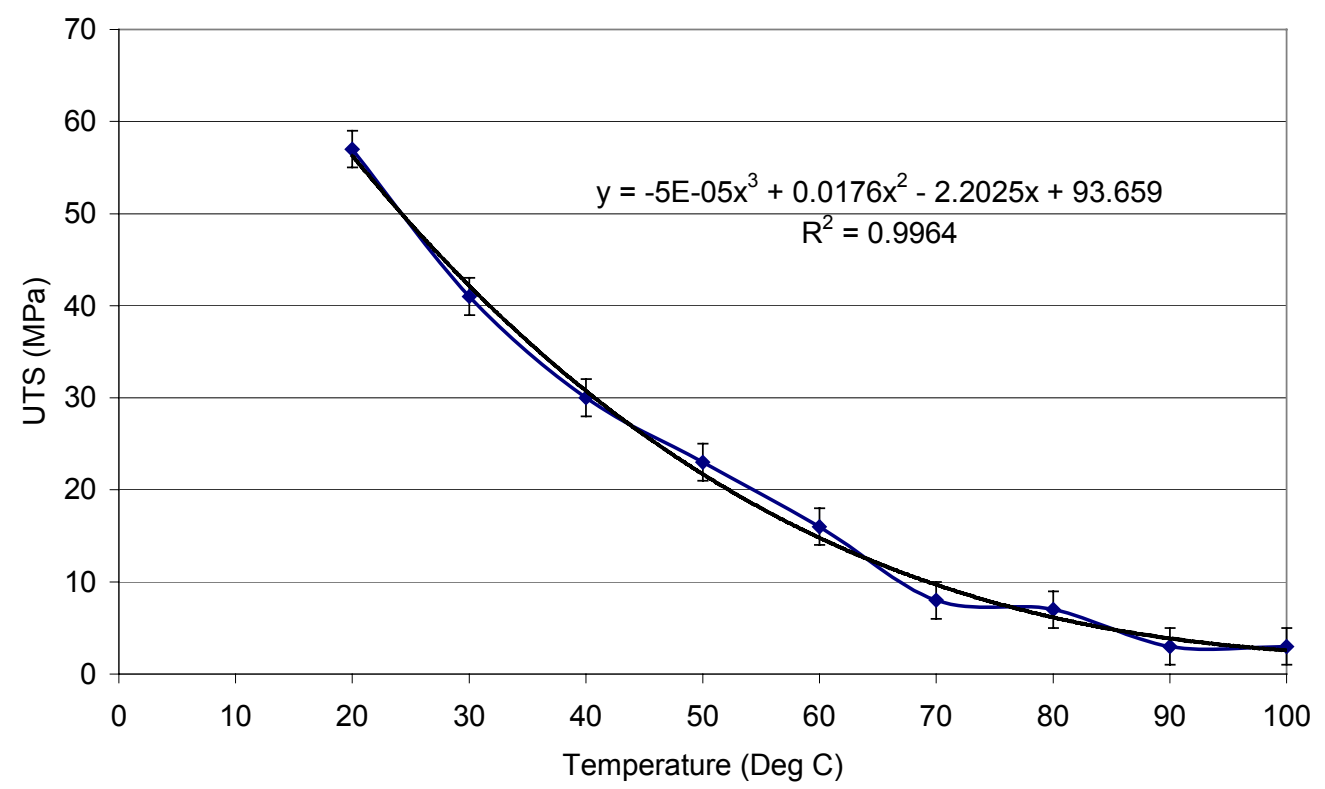

Figure 2. Graph Showing Effect of Elevated Temperatures on SL UTS 


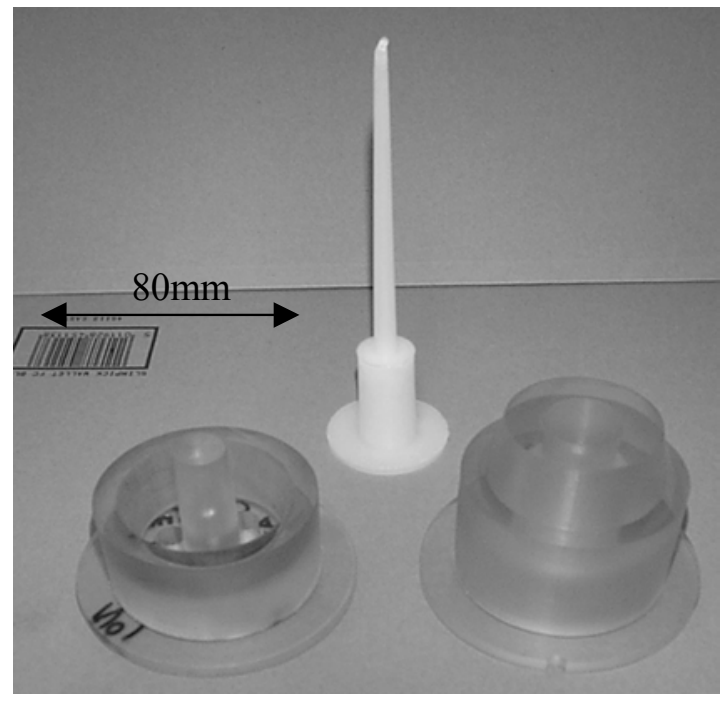

Figure 3. SL tool and a moulding produced from it. 


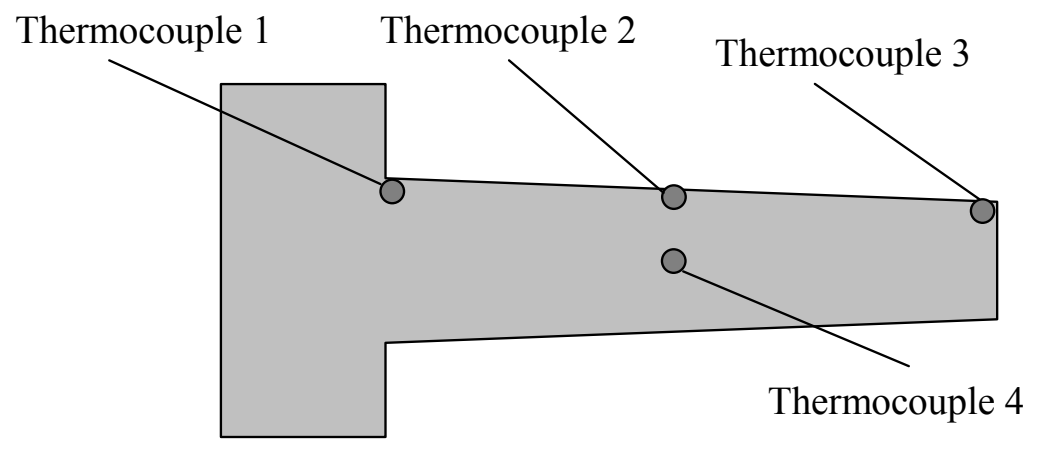

Figure 4. Positions of the thermocouples in the core insert 


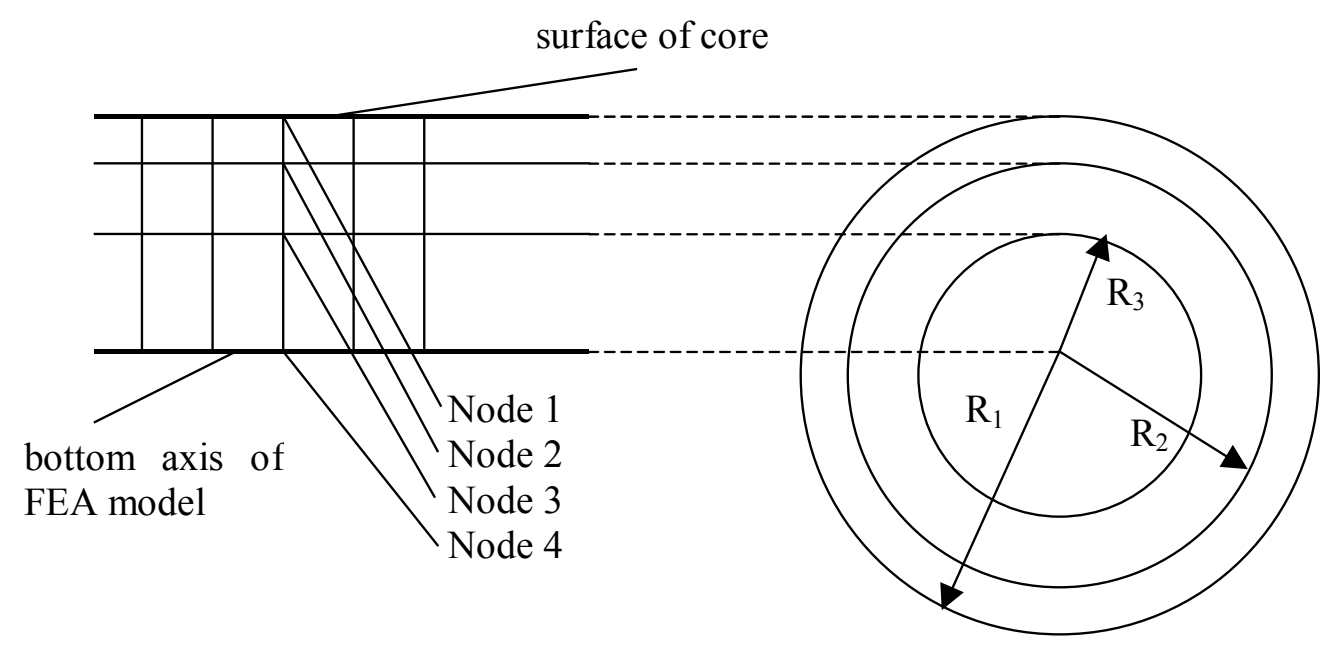

Figure 5. Method for using FEA results to predict tool strength 


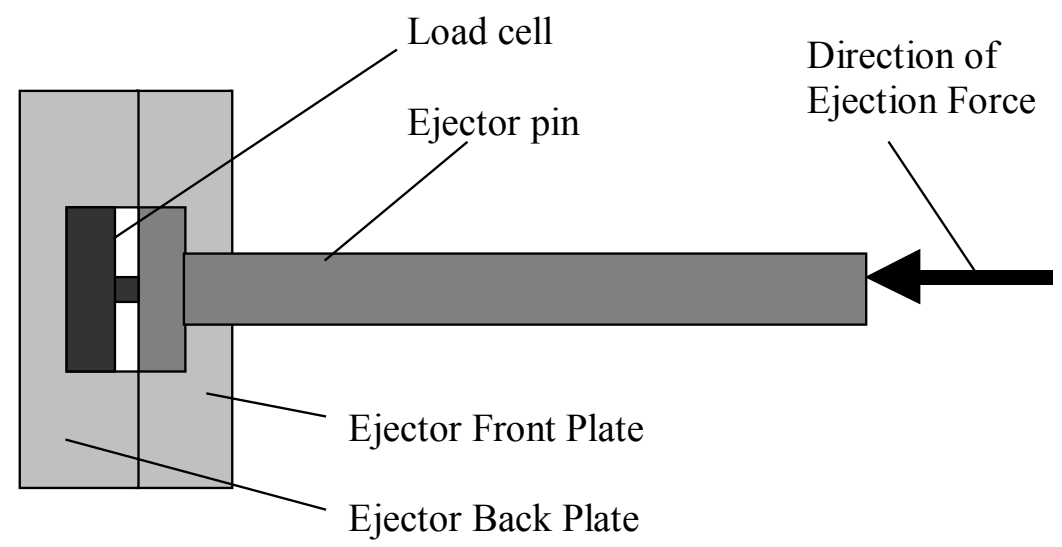

Figure 6. Location of the load cells behind the ejector pins 


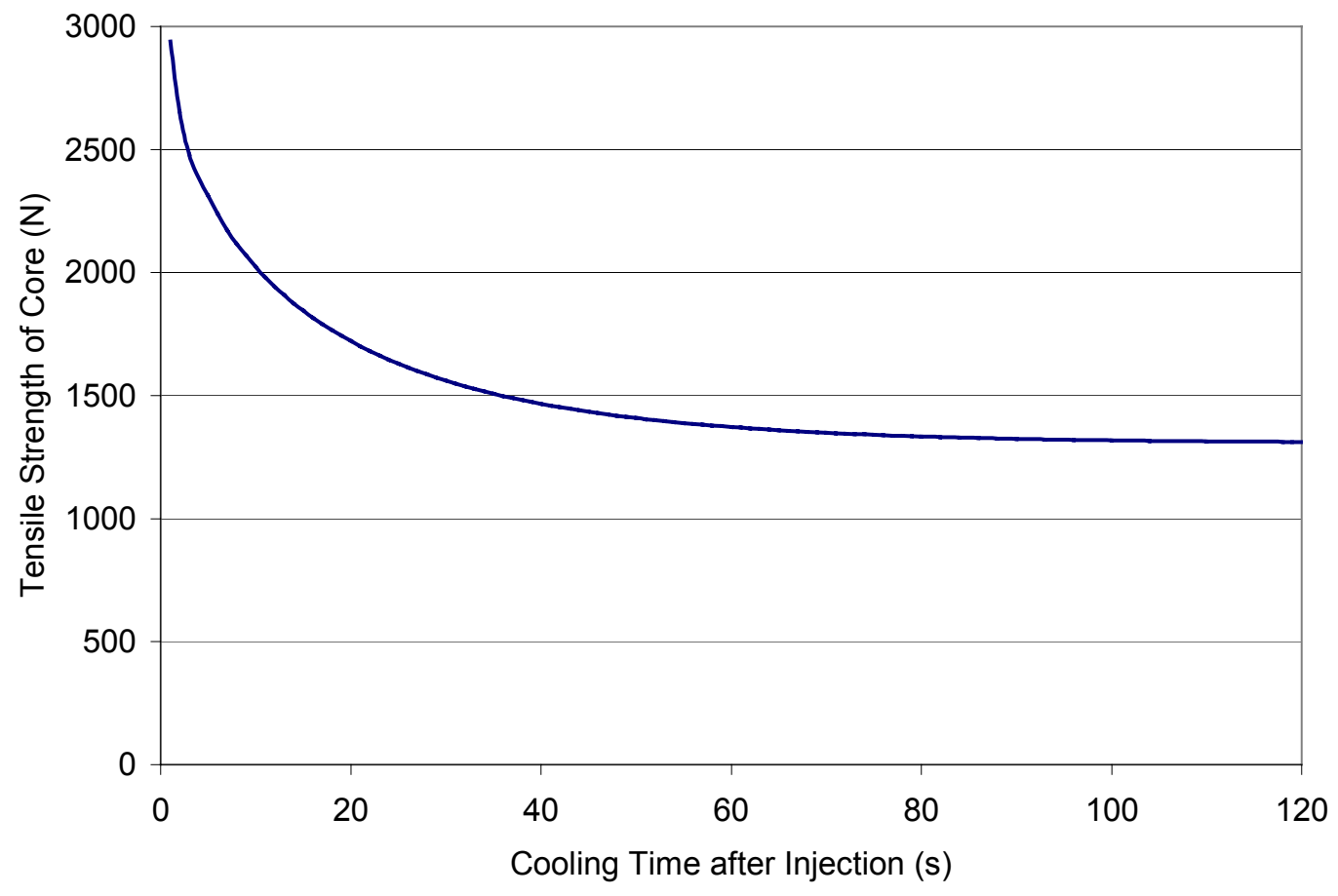

Figure 7. Predicted tool strength at various times after injection 


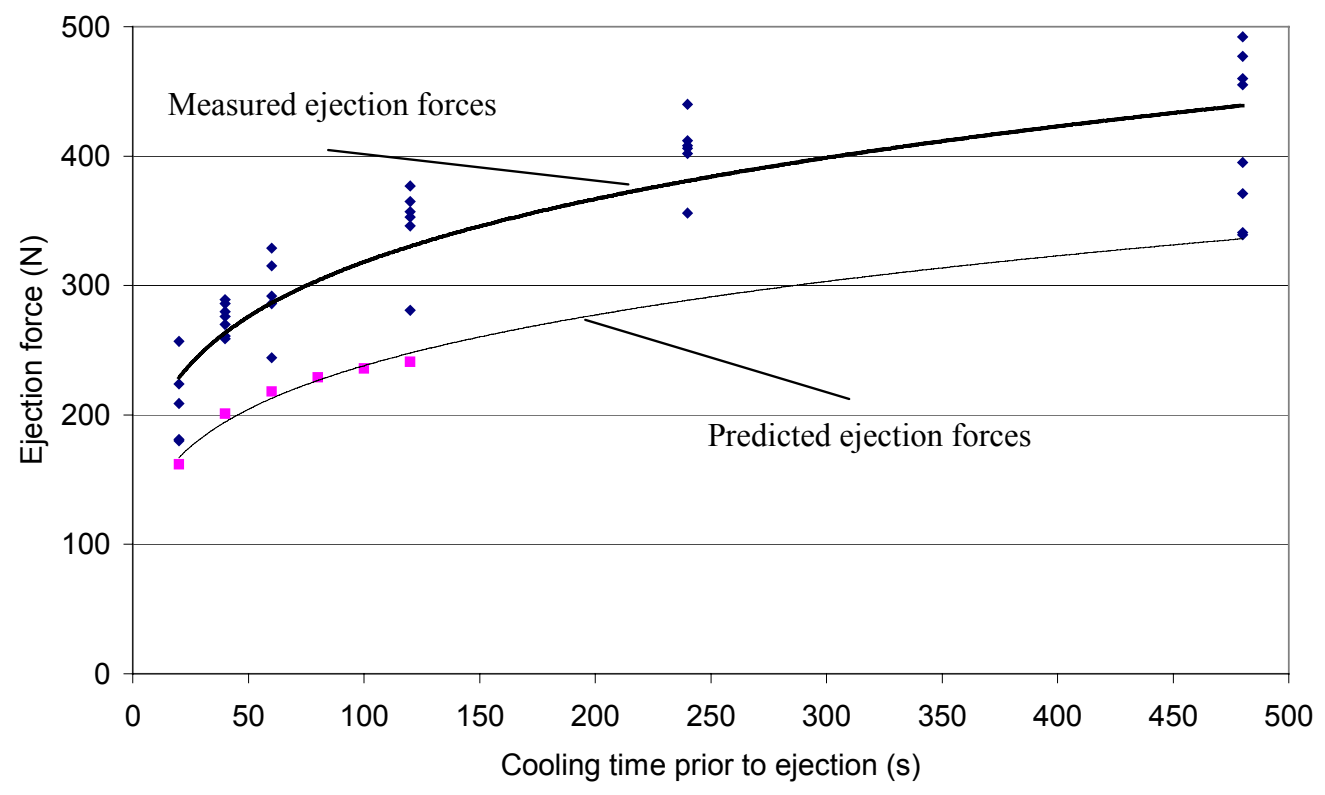

Figure 8. Measured Ejection Forces along with Predicted Values 
Figure 1. Diagram Showing How Contraction of a Moulding onto a core results in Tensile Tool Failure

Figure 2. Graph Showing Effect of Elevated Temperatures on SL UTS

Figure 3. SL tool and a moulding produced from it.

Figure 4. Positions of the thermocouples in the core insert

Figure 5. Method for using FEA results to predict tool strength

Figure 6. Location of the load cells behind the ejector pins

Figure 7. Predicted tool strength at various times after injection

Figure 8. Measured Ejection Forces along with Predicted Values 